\title{
Effects of Lighter Dose of Oxytetracycline on the Accumulation and Degradation of Volatile Fatty Acids in the Process of Thermophilic Anaerobic Digestion of Swine Manure
}

\author{
Zijing Fan, Mei Zhang, Xiaxia Chen, Zhongda Hu, Qihang Shu, Chaosen Jing and Xingzhang Luo * \\ Department of Environmental Science and Engineering, Fudan University, Shanghai 200433, China;

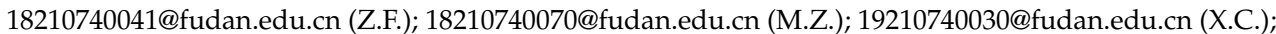 \\ 17210740025@fudan.edu.cn (Z.H.); 19210740047@fudan.edu.cn (Q.S.); 15110740018@fudan.edu.cn (C.J.) \\ * Correspondence: lxz@fudan.edu.cn; Tel.: +86-18621080212
}

check for updates

Citation: Fan, Z.; Zhang, M.; Chen, X.; Hu, Z.; Shu, Q.; Jing, C.; Luo, X. Effects of Lighter Dose of

Oxytetracycline on the Accumulation and Degradation of Volatile Fatty Acids in the Process of Thermophilic Anaerobic Digestion of Swine

Manure. Sustainability 2021, 13, 4014. https://doi.org/10.3390/su13074014

Academic Editor: Lotfi Aleya

Received: 10 March 2021

Accepted: 1 April 2021

Published: 4 April 2021

Publisher's Note: MDPI stays neutral with regard to jurisdictional claims in published maps and institutional affiliations.

Copyright: (c) 2021 by the authors. Licensee MDPI, Basel, Switzerland. This article is an open access article distributed under the terms and conditions of the Creative Commons Attribution (CC BY) license (https:// creativecommons.org/licenses/by/ $4.0 /)$.

\begin{abstract}
Oxytetracycline (OTC) is a commonly used antibiotic in livestock farming for controlling intestinal and respiratory infections in farm animals. However, the absorption of antibiotics by animals is limited, and most antibiotics are excreted in the original form with manure, which will have an impact on the environment. The removal of antibiotics from swine manure could generally be performed via anaerobic digestion (AD). In this study, the effect of oxytetracycline (OTC) at doses of $0.1,0.5$, and $1.0 \mathrm{mg} / \mathrm{L}$ on the thermophilic anaerobic digestion of swine manure $\left(55^{\circ} \mathrm{C}\right)$ in batch digesters was studied. The methane production, volatile fatty acid (VFA) levels, and dissolved organic matter (DOM) were determined and compared with the control $(0 \mathrm{mg} / \mathrm{L}$ of OTC). The results indicate that (1) OTC at $0.1 \mathrm{mg} / \mathrm{L}$ had no inhibitory effect on methane production or on the accumulation of VFAs, while $0.5 \mathrm{mg} / \mathrm{L}$ and $1.0 \mathrm{mg} / \mathrm{L}$ inhibited methane production, with inhibition rates of $4.03 \%$ and $14.12 \%(p<0.05)$, respectively; (2) the VFAs of each reactor peaked on the first day of the reaction, and as the OTC dose increased from 0 to $1.0 \mathrm{mg} / \mathrm{L}$, the maximum VFA accumulation increased from $1346.94 \mathrm{mg} / \mathrm{g}$ to $2370 \mathrm{mg} / \mathrm{g}$ of volatile solids (VS); and (3) oxytetracycline (0.5 and $1.0 \mathrm{mg} / \mathrm{L}$ ) could promote the temporary accumulation of propionic acid, which did, however, not result in significant VFA accumulation. Further, OTC at $1.0 \mathrm{mg} / \mathrm{L}$ can promote DOM production, and therefore, VFA accumulation.
\end{abstract}

Keywords: thermophilic anaerobic digestion; oxytetracycline; volatile fatty acids; methane production; swine manure

\section{Introduction}

Oxytetracycline (OTC) is a commonly used antibiotic in livestock farming for controlling intestinal and respiratory infections in farm animals [1]. The OTC concentrations in manure samples can be in the range of $0.006-136 \mathrm{mg} / \mathrm{L}$ [2]. However, the absorption of antibiotics by animals is limited, and more than $85 \%$ of antibiotics are excreted in their original forms with manure [3]. Antibiotic residues in the environment can affect the growth and metabolism of aquatic and terrestrial organisms, leading to antibiotic resistance in bacteria [4]. Anaerobic digestion is one of the most widely used biological treatment methods for swine farm wastewater to reduce organic solid waste via organic matter degradation and produce biogas [5]. Mesophilic temperature anaerobic digestion and thermophilic anaerobic digestion are two commonly used processes, both with their own sets of advantages and disadvantages. Although few studies have focused on thermophilic anaerobic digestion, compared with digestion at moderate temperatures, thermophilic anaerobic digestion has the advantages of a shorter residence time, a more comprehensive range of organic matter loading, and a smaller digestion tank volume. In addition, the degradation rate of organic matter is higher, resulting in the production of larger amounts of biogas [6,7]. Volatile fatty acids (VFAs), mainly composed of short-chain fatty acids 
(such as formic acid, acetic acid, propionic acid, butyric acid, and valeric acid), are common products of the acidogenesis phase of anaerobic digestion, and their accumulation in the anaerobic system has an impact on biogas production capacity and organic matter degradation [8]. The presence of OTC can lead to the accumulation of VFAs and inhibit the production of methane [4,9].

However, in previous studies, the concentration range of antibiotics such as sulfonamides, tetracyclines, and macrolides was generally high (10-200 mg/L), whereas studies focusing on low OTC concentrations are scarce. In one study, low concentrations of antibiotics did not inhibit anaerobic processes [10]. However, one study has shown that tylosin inhibits the production of methane, even at concentrations as low as $0.01 \mathrm{mg} / \mathrm{L}$ [11]. Similarly, the methane production of cow manure also decreased significantly in the presence of OTC (about $3.0 \mathrm{mg} / \mathrm{L}$ ) and was $52 \%$ lower than in the control digester [12]. Even at low concentrations of antibiotic mixtures $(1.0 \mathrm{mg} / \mathrm{L}$ ET-ST), VFAs begin to accumulate [13]. However, there is a lack of information on the anaerobic digestion of swine manure at low OTC concentrations and high temperatures $\left(55^{\circ} \mathrm{C}\right)$, and to date, it is not clear whether swine manure containing low concentrations of OTC will adversely affect the gas production and antibiotic degradation efficiency during anaerobic treatment.

Researchers have different opinions on the influence of antibiotics on anaerobic reactions in the range of $0-2 \mathrm{mg} / \mathrm{L}$. In this study, we focused specifically on the $0-1 \mathrm{mg} / \mathrm{L}$ range. In this context, we investigated the impacts of low-concentration OTC on the dynamic changes of VFAs in anaerobic fermentation at a higher temperature $\left(55^{\circ} \mathrm{C}\right)$ and the underlying mechanisms. First, we evaluated the effect of different OTC dosages on the production of VFAs in anaerobic fermentation. Second, we assessed the influence of OTC on anaerobic fermentation solubilization and methane production. Finally, we detected the concentration of OTC and analyzed its degradation process. Our results provide a scientific basis for considering the role of antibiotic residues in anaerobic fermentation and optimizing swine manure fermentation systems.

\section{Materials and Methods}

\subsection{Manure Sampling and Activated Sludge}

The activated sludge was obtained from the sedimentation tank of the Songjiang Qingdao Beer wastewater treatment plant in Shanghai City, China. Swine manure and rinses were obtained from a swine farm in Jiaxing, Zhejiang Province, China. The OTC was purchased from Aladdin Industrial Corporation.

\subsection{Experimental Design and Procedure}

Anaerobic experiments were carried out to evaluate the influence of various OTC levels in manure on thermophilic anaerobic digestion. The characteristics of the raw materials are listed in Table 1. In this study, four groups of reactors-R1, R2, R3, and R4-were established, with corresponding OTC concentrations of $0,0.1,0.5$, and $1.0 \mathrm{mg} / \mathrm{L}$, respectively. The schematic diagram for the experimental device is shown in Figure 1. Each reactor had a digestion liquid sampling port sealed with a rubber plug at the bottom and a gas sampling port connected to a gas collection bag at the top. Each group was subjected to anaerobic conditions ( $1.2 \mathrm{~L}$ total volume, $1 \mathrm{~L}$ working volume, $200 \mathrm{rpm}$ stirring speed) in a water bath at $55 \pm 0.5^{\circ} \mathrm{C}$ for 30 days. On the basis of the sludge loading of the anaerobic digestion, $100 \mathrm{~g}$ of sludge and $250 \mathrm{~g}$ of swine manure were added to different reactors and diluted with $1 \mathrm{~L}$ of the rinse solution, resulting in a solid content of approximately $7 \%$ and a $\mathrm{C} / \mathrm{N}$ ratio of 13.85 . In the test group, $1.0,5.0$, and $10.0 \mathrm{~mL}$ of OTC stock solution $(100 \mathrm{mg} / \mathrm{L})$ were added, whereas the control group did not receive OTC. To maintain anaerobic conditions, prior to the experiment, the reactors were flushed with nitrogen. During the entire anaerobic process, biogas and mixed solutions were collected regularly. All samples were collected in triplicate. 
Table 1. Initial substrate and inoculum characteristics.

\begin{tabular}{ccccc}
\hline Parameter & Unit & Inoculum Sludge & Swine Manure & $\begin{array}{c}\text { Inoculum Sludge + Swine } \\
\text { Manure + Rinse Solution }\end{array}$ \\
\hline Total solids (TS) & $\%$ & 22.92 & 23.54 & 7.00 \\
Volatile solids (VS) & $\%$ & 54.42 & 74.59 & 66.87 \\
Total organic carbon (TOC) & $\mathrm{mg} / \mathrm{L}$ & 52.36 & 6901.21 & 4964.81 \\
Total nitrogen (TN) & $\mathrm{mg} / \mathrm{L}$ & 178.04 & 1201.02 & 358.48 \\
C/N & - & $<1$ & 5.75 & 13.85 \\
pH & - & 7.41 & 7.53 & 7.62 \\
\hline
\end{tabular}

Note: $\mathrm{TOC}=$ total organic carbon, $\mathrm{TN}=$ total nitrogen, $\mathrm{C} / \mathrm{N}=$ total organic carbon $/$ total nitrogen, $\mathrm{VS}=$ volatile solids, and TS $=$ total solids.

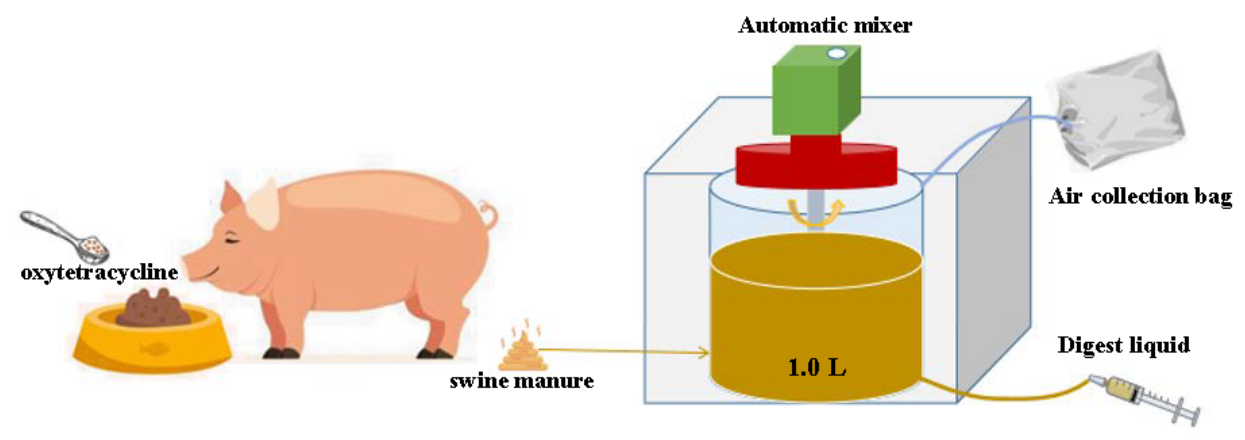

Figure 1. Schematic diagram of the experimental device.

\subsection{Analytical Methods}

\subsubsection{Basic Indicators}

Samples were taken at 1 h, 3 h, 6 h, 12 h, 24 h, 2 d, $3 \mathrm{~d}, 5$ d, 8 d, 15 d, 20 d, and $30 \mathrm{~d}$. The digestive juice was centrifuged at $5000 \mathrm{rpm}$ for $15 \mathrm{~min}$, and the clarified supernatants were used to measure the $\mathrm{pH}$, total organic carbon (TOC), total nitrogen (TN), and VFAs. The $\mathrm{pH}$ was measured with a calibrated $\mathrm{pH}$ meter (AS600, Shanghai As One Trading Co., Ltd. China). The total solids (TS) and volatile solids (VS) were determined according to the American Public Health Association (APHA) standard methods [14]. The total organic carbon (TOC) and total nitrogen (TN) were tested by a TOC analyzer (TOC-L CPH, Shimadzu, Japan). The excitation emission matrix (EEM) fluorescence spectra were used to detect dissolved organic matter (DOM) via fluorescence spectrometry (Horiba, Japan).

Before measuring the VFAs, the liquid sample was diluted and filtered through a $0.45 \mu \mathrm{m}$ filter membrane. Subsequently, $0.9 \mathrm{~mL}$ of the liquid was taken, and $0.1 \mathrm{~mL}$ of $30 \%$ phosphoric acid was added to decrease the $\mathrm{pH}$ to 3.0. Next, the VFAs (acetic acid, propionic acid, butyric acid, isobutyric acid, valeric acid, and isovaleric acid) were detected using a gas chromatograph (GC, 2010Plus, Shimadzu Corporation, Japan) equipped with a flame ionization detector (FID) and an Agilent DB-WAX UI column. The chromatographic column was first kept at $80^{\circ} \mathrm{C}$ for $1 \mathrm{~min}$, then heated to $180^{\circ} \mathrm{C}$ at a rate of $10^{\circ} \mathrm{C} / \mathrm{min}$ and held for $5 \mathrm{~min}$. The temperature of the detector and injection port were both maintained at $250{ }^{\circ} \mathrm{C}$, with nitrogen gas flowing at $50 \mathrm{~mL} / \mathrm{min}$, hydrogen at $40 \mathrm{~mL} / \mathrm{min}$, and air at $400 \mathrm{~mL} / \mathrm{min}$ as carrier gases.

\subsubsection{Biogas Measurement}

The biogas was collected in an air collection bag, and its volume was measured via the water displacement method. The methane in the bag was analyzed by a gas chromatograph equipped with a thermal conductivity detector (GC-960, Haixin, China) and column (Haixin $\mathrm{ST})$. The carrier gas was $\mathrm{He}$, and the temperatures of the injector, detector, and oven were 120,110 , and $120^{\circ} \mathrm{C}$, respectively. The cumulative biogas production during anaerobic 
digestion was modeled using the modified Gompertz equation [15], which is defined as follows:

$$
\mathrm{Y}(\mathrm{t})=\mathrm{Mm} \times \exp \left\{-\exp \left[\frac{R m \times \mathrm{e}}{\mathrm{Mm}}(\lambda-\mathrm{t})+1\right]\right\}
$$

where $Y(t)$ is the cumulative methane production measurement at time $t(d), M m$ is the maximum cumulative methane volume $(\mathrm{mL}), R m$ is the maximum methane production rate $(\mathrm{mL} / \mathrm{d}), \lambda(\mathrm{d})$ is the lag time, and e equals 2.72 . Additionally, these models were evaluated by statistical indicators of the coefficient of determination $\left(R^{2}\right)$.

\subsubsection{Ultra-Performance Liquid Chromatography-Tandem Mass Spectrometry}

The OTC was extracted using the method of Dorival [16]. The ESI+ mode and internal standard method were used, and the analyzed sample injection was repeated five times. The concentration of OTC was quantified using a Xevo TQ-XS Waters LC-MS/MS with a Waters ACQUITY UPLC BEH C18 column $(1.7 \mu \mathrm{m})$, using the chromatographic separation of the binary mobile phase gradient, the mobile phase with a $0.1 \%(v / v)$ formic acid aqueous solution (solvent A), and methanol (solvent $\mathrm{B}$ ). The flow rate was $0.3 \mathrm{~L} / \mathrm{min}$, the column was maintained at $30^{\circ} \mathrm{C}$, and the injection volume was $20 \mu \mathrm{L}$. The mass spectrometer was a triple quadrupole mass spectrometer equipped with an ESI source and used the Masslynex software to complete instrument control as well as data acquisition and evaluation. The instrument parameters were as follows: scan time, $0.5 \mathrm{~s}$; scan width, 0.2 ; collision gas flow (argon), $0.15 \mathrm{~mL} / \mathrm{min}$; spray voltage, $3.5 \mathrm{kV}$; cone voltage, $75 \mathrm{~V}$; desolventizing gas temperature, $400{ }^{\circ} \mathrm{C}$; desolvent gas flow rate, $800 \mathrm{~L} / \mathrm{hr}$; and cone gas flow rate, $150 \mathrm{~L} / \mathrm{hr}$.

For the most part, the degradation of organic pollutants followed a simple first-order kinetic model, whose expression is as follows:

$$
\mathrm{dC} / \mathrm{dt}=-\mathrm{kC} \text { and } \mathrm{C}_{\mathrm{t}}=\mathrm{C}_{0} \mathrm{e}^{\wedge}(-\mathrm{kt})
$$

where $t$ is time (day), $C_{0}$ and $C_{t}$ are the initial concentration and concentration at time $t$, and $\mathrm{k}$ is the degradation rate constant (day 1 ). The half-life can be expressed as follows:

$$
\mathrm{t}(1 / 2)=\ln 2 / \mathrm{k}
$$

\subsection{Statistical Analysis}

Differences in methane contents among the control and OTC-containing serum bottles were determined by analysis of variance (ANOVA) using SPSS v. 20 (IBM, Armonk, NY, USA). Significance was accepted at probabilities $(p)$ of 0.05 or less for all analyses. The software Origin 2020b (OriginLab Corp., Northampton, MA, USA) was used to plot the graphs.

\section{Results}

\subsection{Effects of OTC on Methane Production}

The accumulation of methane produced by anaerobic digestion at different OTC levels is shown in Figure 2. Methane production increased rapidly from 0 to $15 \mathrm{~d}$ in all cases, followed by a less rapid increase until the end of anaerobic digestion. 

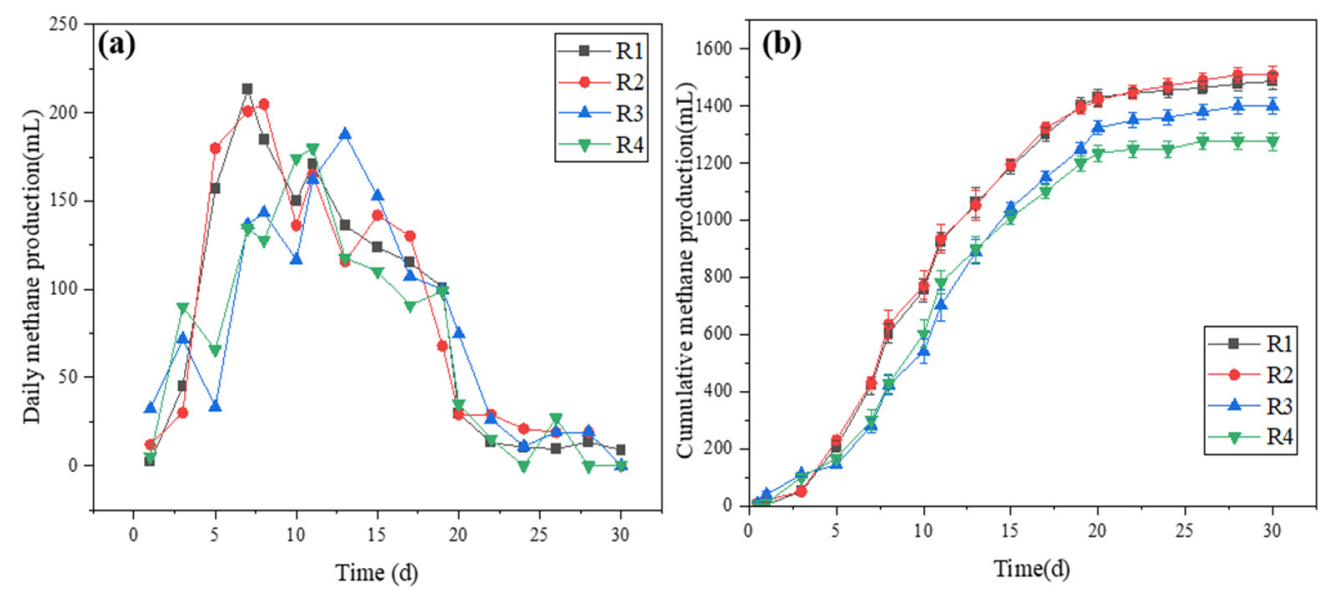

Figure 2. Daily (a) and cumulative (b) methane production for R1-R4.

On the first day, the four groups produced only low amounts of gas, most likely because in the early stage of anaerobic fermentation, microorganisms had not adapted to the wastewater environment [17]. On day 2, however, the anaerobic fermentation microorganisms started to adapt to the different conditions, and the organic matter decomposition rate increased, resulting in methane production. Groups R1, R2, R3, and R4 reached the peak of methane production at days $7,8,13$, and 11, respectively, with values of 214.33, $205.01,187.67$, and $179.67 \mathrm{~mL}$, respectively. It can be observed that the gas production peaks of R3 and R4 had a lag period. From the 20th day to the end of anaerobic digestion, the gas production of all groups began to decline. This may be due to the continuous consumption of organic matter in the raw materials, which led to biogas production continuously decreasing throughout the experiment, which has also been observed in a previous study [18].

Methane production was negatively affected by the OTC concentration. Based on Figure 2, the cumulative methane volume of the control group was slightly higher than that of the experimental groups R3 and R4 during the entire operation of the system.

The cumulative methane production levels of groups R2, R3, and R4 were 1510.10, 1400.67 , and $1277.33 \mathrm{~mL}$, respectively, whereas that of the control group was $1487.36 \mathrm{~mL}$. The methane production of $\mathrm{R} 3$ and $\mathrm{R} 4$ decreased by $86.69 \mathrm{~mL}$ and $210.03 \mathrm{~mL}$, respectively, and the inhibition rates were $4.03 \%$ and $14.12 \%(p<0.05)$, respectively. Peak gas production was at days 7, 8, 13, and 11 for groups R1, R2, R3, and R4, respectively. Groups R3 and R4 not only had lower peak gas productions compared with the control group, but also delays in time (by 6 and 4 days, respectively). This can be explained by the fact that OTC inhibits bacterial protein synthesis by binding to the $30 \mathrm{~S}$ ribosomal subunit and is mainly effective for gram-negative organisms. Therefore, OTC affected the activity of microorganisms during anaerobic treatment, thereby affecting methane production [9]. Group R2 showed no inhibition of anaerobic fermentation; methane production was even slightly promoted. Most likely, the OTC concentration of the R2 group had little effect on the activity of methanogens, and OTC was used as a carbon source for microorganisms in the anaerobic process [18].

A Gompertz modified equation was used to simulate the cumulative methane production curve. The key simulation parameters of the maximum methane production potential $(\mathrm{Mm})$, maximum rate of methane production $(\mathrm{Rm})$, lag period $(\lambda)$, and correlation coefficient $\left(R^{2}\right)$ are shown in Table 2 . The values of $R^{2}$ were all $>0.997$, indicating that the cumulative methane yields fit the Gompertz modified model. The potential maximum methane production $\mathrm{G}_{\max }$ followed the order $\mathrm{R} 2(1523.78 \pm 14.02 \mathrm{~mL})>\mathrm{R} 1$ $(1501.92 \pm 13.07 \mathrm{~mL})>\mathrm{R} 3(1450.83 \pm 20.01 \mathrm{~mL})>\mathrm{R} 4(1306.06 \pm 14.02 \mathrm{~mL})$. The maximum rate of methane production $\mathrm{Rm}$ followed the order R1 $>\mathrm{R} 2>\mathrm{R} 4>\mathrm{R} 3$, indicating that an OTC concentration of $0.1 \mathrm{mg} / \mathrm{L}$ had no inhibitory effect on the methanogenesis and methanogenesis rate. In contrast, OTC levels of 0.5 and $1 \mathrm{mg} / \mathrm{L}$ had a certain in- 
hibitory effect on methanogenesis and, consequently, the methanogenesis rate. In the experimental concentration range, higher OTC contents had higher inhibitory impacts on biogas production.

Table 2. Key kinetic parameters during anaerobic methane production for reactor groups R1-R4.

\begin{tabular}{ccccc}
\hline Key Parameters & $\mathbf{R} \mathbf{1}(\mathbf{0} \mathbf{~ m g} / \mathbf{L})$ & $\mathbf{R} \mathbf{( 0 . 1} \mathbf{~ m g} / \mathbf{L})$ & $\mathbf{R} 3 \mathbf{( 0 . 5} \mathbf{~ m} / \mathbf{L})$ & $\mathbf{R 4}(\mathbf{1 . 0} \mathbf{~ m g} / \mathbf{L})$ \\
\hline $\mathrm{Mm}(\mathrm{mL})$ & $1501.92 \pm 13.07$ & $1523.78 \pm 14.02$ & $1450.83 \pm 20.01$ & $1306.06 \pm 14.02$ \\
$\mathrm{Rm}(\mathrm{mL} / \mathrm{d})$ & $122.99 \pm 3.90$ & $119.64 \pm 3.99$ & $103.29 \pm 4.09$ & $104.41 \pm 4.01$ \\
$\mathrm{R}^{2}$ & 0.998 & 0.998 & 0.997 & 0.997 \\
$\lambda(\mathrm{d})$ & $3.51 \pm 0.19$ & $3.25 \pm 0.21$ & $4.20 \pm 0.26$ & $3.87 \pm 0.23$ \\
$\mathrm{Mm}(\mathrm{mL})$ & $1501.92 \pm 13.07$ & $1523.78 \pm 14.02$ & $1450.83 \pm 20.01$ & $1306.06 \pm 14.02$ \\
$\mathrm{Rm}(\mathrm{mL} / \mathrm{d})$ & $122.99 \pm 3.90$ & $119.64 \pm 3.99$ & $103.29 \pm 4.09$ & $104.41 \pm 4.01$ \\
\hline
\end{tabular}

Note: $\mathrm{Mm}=$ maximum cumulative methane volume $(\mathrm{mL}), \mathrm{Rm}=$ maximum methane production rate $(\mathrm{mL} / \mathrm{d})$ and $\lambda(\mathrm{d})=$ lag time.

Similar findings have been reported in the literature. For example, Yin indicated that the value of the Rm parameter decreased as the concentration of CTC or OTC in the sludge increased [17]. In another study [19], the authors showed that an OCT concentration of $3.1 \mathrm{mg} / \mathrm{L}$ could reduce the production of $\mathrm{CH}_{4}$ by $27 \%$. However, another study found no significant inhibitory effect at OTC concentrations of $30-90 \mathrm{mg} / \mathrm{L}$ [9]. These inconsistencies can be attributed to differences in the history of the sludge used and the operating conditions, including inoculum and manure sources, the inoculum/fertilizer ratio, antibiotic concentration, reactor size, and batch experiment or continuous operation [2]. In the current work, the effects of OTC at 0.5 and $1.0 \mathrm{mg} / \mathrm{L}$ were obvious, which implied that these concentrations would prolong the lag phase and have a certain inhibitory effect on methane production.

\subsection{Effect of OTC on $p H$ and VFA Production from Anaerobic Digestion}

The $\mathrm{pH}$ variations along the digestion process are shown in Figure 3f. The initial $\mathrm{pH}$ values for all reactors ranged between 7.42 and 7.60, which are considered suitable for anaerobic digestion [20]. The $\mathrm{pH}$ value of each reactor gradually increased within the first $3 \mathrm{~h}$, most likely because the anaerobic system entered the first stage of anaerobic fermentation, and nitrogen-containing compounds such as protein and urea began to be hydrolyzed and fermented by the fermenting bacteria to form ammonia nitrogen [21], leading to an increase in the $\mathrm{pH}$. Subsequently, the $\mathrm{pH}$ of each reactor gradually decreased to about 6.5 , probably because the anaerobic reaction system converted the intermediate products produced in the early stage into VFAs, $\mathrm{H} 2$, and $\mathrm{CO}_{2}$ under the action of hydrogenproducing acetogens [22]. The reaction system begins to produce and accumulate acids, causing the $\mathrm{pH}$ to drop slowly. In the following phase, the methanogens use, for example, acetic acid or methanol as a substrate and convert it into methane, thereby reducing the acidity in the system [22]. In addition, anaerobic microorganisms convert a large amount of organic nitrogen into ammonia nitrogen, which is promoted under high temperatures. The increase in alkalinity of the anaerobic digestion fluid can effectively neutralize the acid generated and increase the $\mathrm{pH}$ value of the digestion fluid. Therefore, the $\mathrm{pH}$ of each reactor began to rise gradually after the fifth day. The $\mathrm{pH}$ values of R1, R2, R3, and R4 increased from 6.70, 6.83, 6.81, and 6.82 to 8.36, 8.42, 8.37, and 8.48, respectively. Similarly, Yin found that after the methanogenesis stage, the final $\mathrm{pH}$ of the digestion solution increased from 7.7-7.9 to 8.2-8.3 [18]. In a similar study, high concentrations of antibiotics caused a sharp decrease in $\mathrm{pH}$ in the initial anaerobic stage [23]. However, the OTC concentrations used in our experiment were relatively low, and the $\mathrm{pH}$ change trends of all reactors were roughly the same. The $\mathrm{pH}$ of each group was between 8.3 and 8.5 after digestion, indicating that the reaction system was relatively stable. 

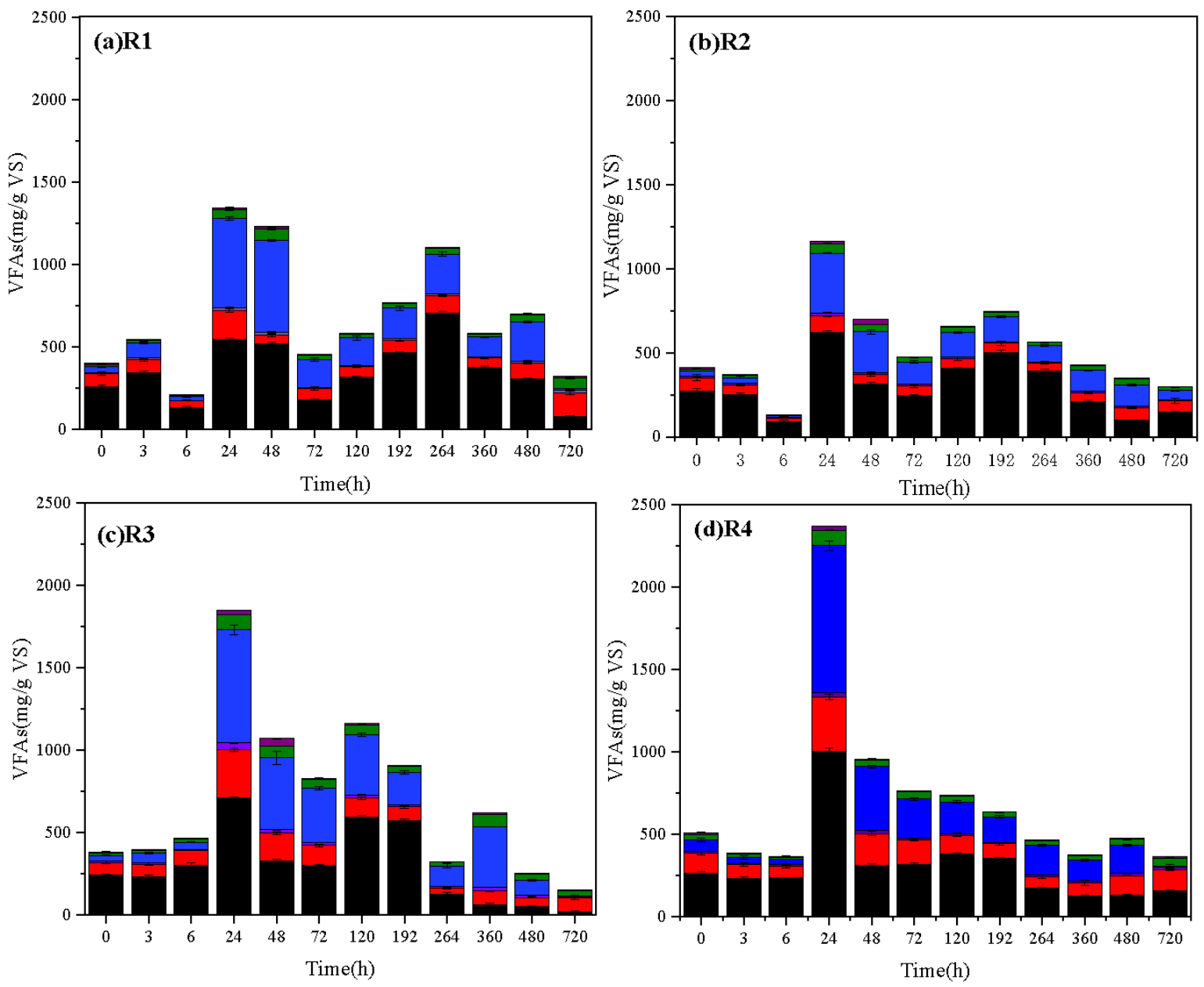

Acetic acid

Propionic acid

Butyric acid

Isobutyric acid $\square$ Isovaleric acid Valeric acid
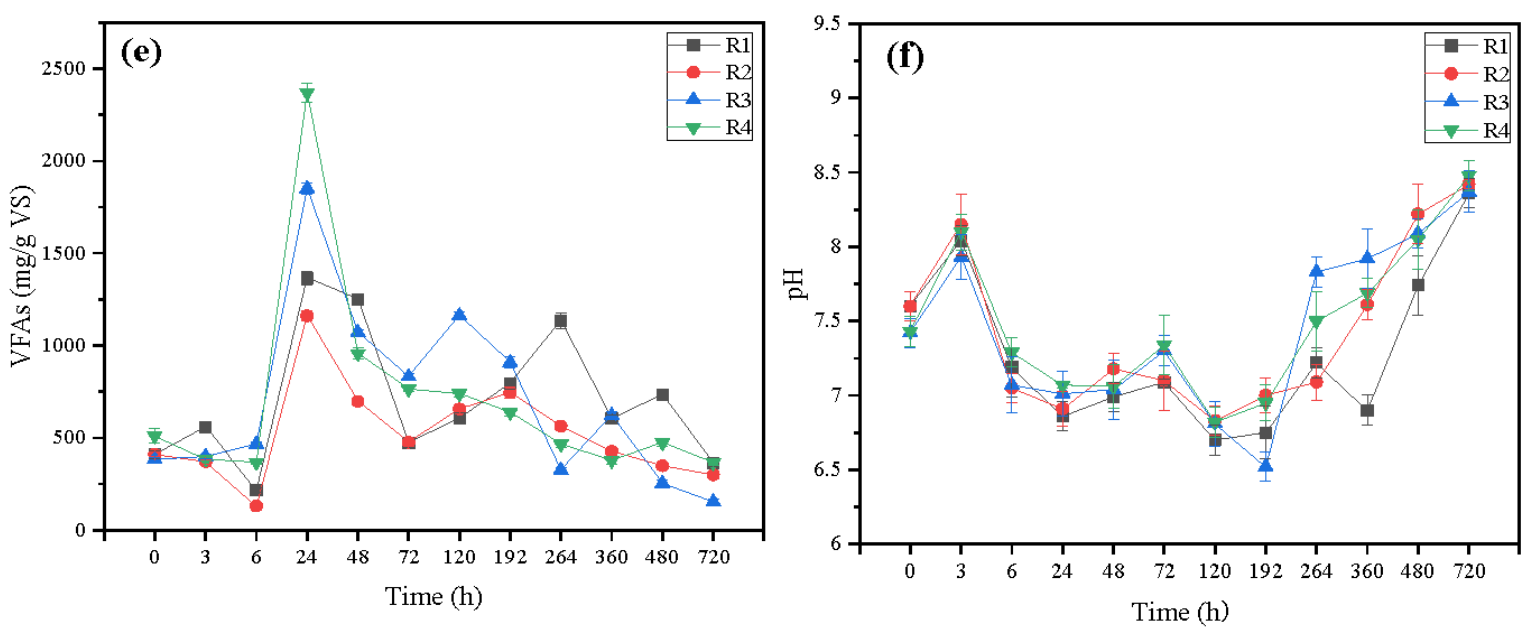

Figure 3. Changes of volatile fatty acid (VFA) components in (a) R1 (control test), (b) R2 (with $0.1 \mathrm{mg} / \mathrm{L}$ oxytetracycline (OTC)), (c) R3 (with $0.5 \mathrm{mg} / \mathrm{L} \mathrm{OTC),} \mathrm{and} \mathrm{(d)} \mathrm{R4} \mathrm{(with} 1 \mathrm{mg} / \mathrm{L} \mathrm{OTC),} \mathrm{as} \mathrm{well} \mathrm{as} \mathrm{the} \mathrm{changes} \mathrm{in} \mathrm{total} \mathrm{VFAs} \mathrm{(e)} \mathrm{and} \mathrm{pH} \mathrm{value}$ (f) of R1-R4.

VFAs are intermediate compounds formed during the anaerobic degradation of manure [18]. In this study, acetic acid, propionic acid, butyric acid, isobutyric acid, valeric acid, and isovaleric acid were measured (Figure $3 \mathrm{a}-\mathrm{d}$ ). The total VFAs produced in the reactor are shown in Figure 3e. The VFA concentration in all reactors first increased and then decreased, reaching the maximum on day 1 at 1346.94,1160.71, 1850.14, and $2232.79 \mathrm{mg} / \mathrm{g}$ 
VS, respectively. The increase in VFA production and the early peaks may have been due to the dissolution and hydrolysis of organic matter [24], and high temperature conditions can accelerate this process. For example, in another study, the VFAs of the anaerobic system with roxithromycin reached the maximum on day 3 (control group) and day 6 (experimental group) under moderate temperatures and anaerobic conditions [25]. At the stage of acid production $(1 \mathrm{~d})$, the increase in VFA production was mainly due to the increase in acetic acid and butyric acid, which was similar to previous findings with sulfadiazine and chlortetracycline $[18,26]$. This leads us to infer that the type of anaerobic fermentation of swine manure and sludge was butyric acid-type fermentation [15], and the concentration of butyric acid accounted for more than $80 \%$ of the total concentration of VFAs. The maximum VFA concentrations of R1 and R2 were 1346.94 and $1160.71 \mathrm{mg} / \mathrm{g}$ VS, respectively, indicating that $0.1 \mathrm{mg} / \mathrm{L}$ OTC had little effect on the VFA changes in the anaerobic system. The maximum VFA concentrations in the R3 and R4 reactors were 1850.14 and $2232.79 \mathrm{mg} / \mathrm{g} \mathrm{VS}$, respectively, and 1.37 and 1.65 times than that of the control, respectively, indicating that 0.5 and $1 \mathrm{mg} / \mathrm{L}$ OTC can promote the production of VFAs. From day 2 to day 7 of digestion, the concentration of total VFAs in each reactor decreased, along with the levels of butyric acid, while the acetic acid concentration gradually increased. Most likely, in the acetylation stage of the system, VFAs were further converted to acetic acid, carbon dioxide, and hydrogen by acetogenic bacteria [27]. This process consumes the acid accumulated in the system and, at the same time, butyric acid is converted into acetic acid. Therefore, the concentration of butyric acid decreases while that of acetic acid gradually increases. From day 1 to day 5 , the propionic acid concentrations of R3 and R4 were significantly greater than that of the control group. For example, the concentration of R1 propionic acid was $177.12 \mathrm{mg} / \mathrm{g}$ VS, while those in R3 and R4 were 294.25 and $327.91 \mathrm{mg} / \mathrm{g}$ VS on the first day, respectively. Similarly, sulfadiazine has been reported to increase the concentration of propionic acid from anaerobic fermentation [26]. One study stated that propionic acid is an unfavorable substrate for microorganisms, and getting the degradation reaction of propionic acid to proceed spontaneously is difficult. This is because propionate degradation is initially limited by thermodynamics, as the Gibbs free energy for the conversion of propionic acid to acetate is $76 \mathrm{~kJ} / \mathrm{mol}$, and therefore, this reaction cannot occur spontaneously [28]. The accumulation of propionic acid in VFAs is directly related to the processing capacity of the anaerobic digestion system. Such accumulation will lead to a decrease in the gas production of the system, which is usually a sign of system unbalance [29].

In our study, OTC at concentrations of 0.5 and $1.0 \mathrm{mg} / \mathrm{L}$ could promote the accumulation of propionic acid in the system, thereby promoting the transformation from butyric acid fermentation to propionic acid fermentation. This may, in turn, inhibit the degradation of propionic acid, causing it to temporarily accumulate in the reaction system, thereby inhibiting the anaerobic digestion system. When the digestion is complete, most of the VFAs are degraded, which is in agreement with previous findings [18]. In our experiment, the highest degradation rates were $0.76,0.74,0.92$, and 0.85 . However, propionic acid was still the main component of VFAs, most likely because propionic acid was difficult to degrade.

The VFA concentrations of each reactor after the reaction were 244.36, 298.61, 152.18, and $365.81 \mathrm{mg} / \mathrm{g}$ VS, without any significant differences among the final VFA contents of each reactor. In summary, compared with the control group, the other three reactors showed no significant impact on butyrate-type fermentation, although in R3 and R4, the accumulation of propionic acid was affected. Group R2 (0.1 mg/L OTC) showed no significant effect on VFAs, while R3 ( $0.5 \mathrm{mg} / \mathrm{L}$ OTC) showed an increased peak value of VFAs and a promoted temporary accumulation of propionic acid; however, VFAs were not accumulated. Group R4 (1.0 mg/L OTC) also showed an increased peak value of VFAs and promoted the temporary accumulation of propionic acid. At the end of the reaction, the VFA concentration was slightly higher than that of the control group with insignificant accumulation. 


\subsection{Effects of OTC on the Solubilization Process and the Entire Anaerobic Reaction}

Solubilization refers to the incipient phase of anaerobic fermentation and is commonly considered as a speed-limiting step [30]. Once the solid releases more dissolved total organic carbon (TOC) into the solution, more bioavailable substrates will be produced. As shown in Figure 4a, the TOC concentrations of R1-R4 were 4850.8, 4759.3, 4925.6, and $4898.2 \mathrm{mg} / \mathrm{L}$ after $3 \mathrm{~h}$ of the reaction, respectively. On the second day, these values were 5000.2, 5193.4, 5490.5, and 5259.8 mg/L, following the order R3 > R4 > R2 > control. Lower TOC values in the control (R1) indicate that the addition of OTC can increase the concentration of TOC.
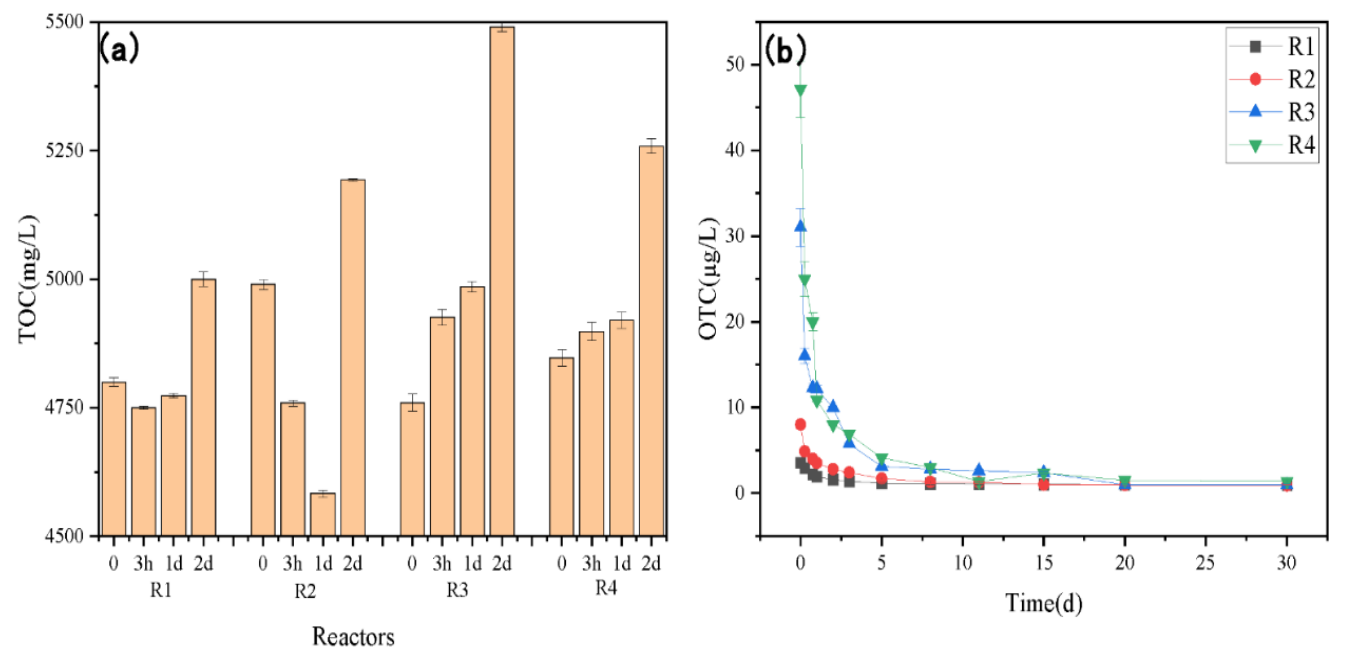

Figure 4. Changes in total organic carbon (TOC) (a) and OTC concentration (b) in the liquid phase of groups R1-R4.

The changes in DOM in the fermentation broth were further analyzed by EEM fluorescence spectroscopy, and the results are shown in Figure 5a-d. We observed one major fluorescence peak from the fluorescence spectra, located at Ex/Em 260-280/250 (signed as Peak A). The peak size of each reactor was 1465, 2010, 2580, and 2570, respectively. Previous studies have shown that Peak A is geared toward tyrosine substances, which are generally biodegradable [31]. Compared with the control, in all treatments, the fluorescence intensities of Peak A were significantly increased, following the order R3 $>$ R4 $>$ R2 $>$ control. The continuous release of more organic substrates into the fermentation broth may lead to increased fluorescence intensity [32]. Our results show that OTC increased the biodegradability of soluble organic matter and facilitated its dissolution, thus providing more soluble organic matter as substrate for the production of VFAs. 

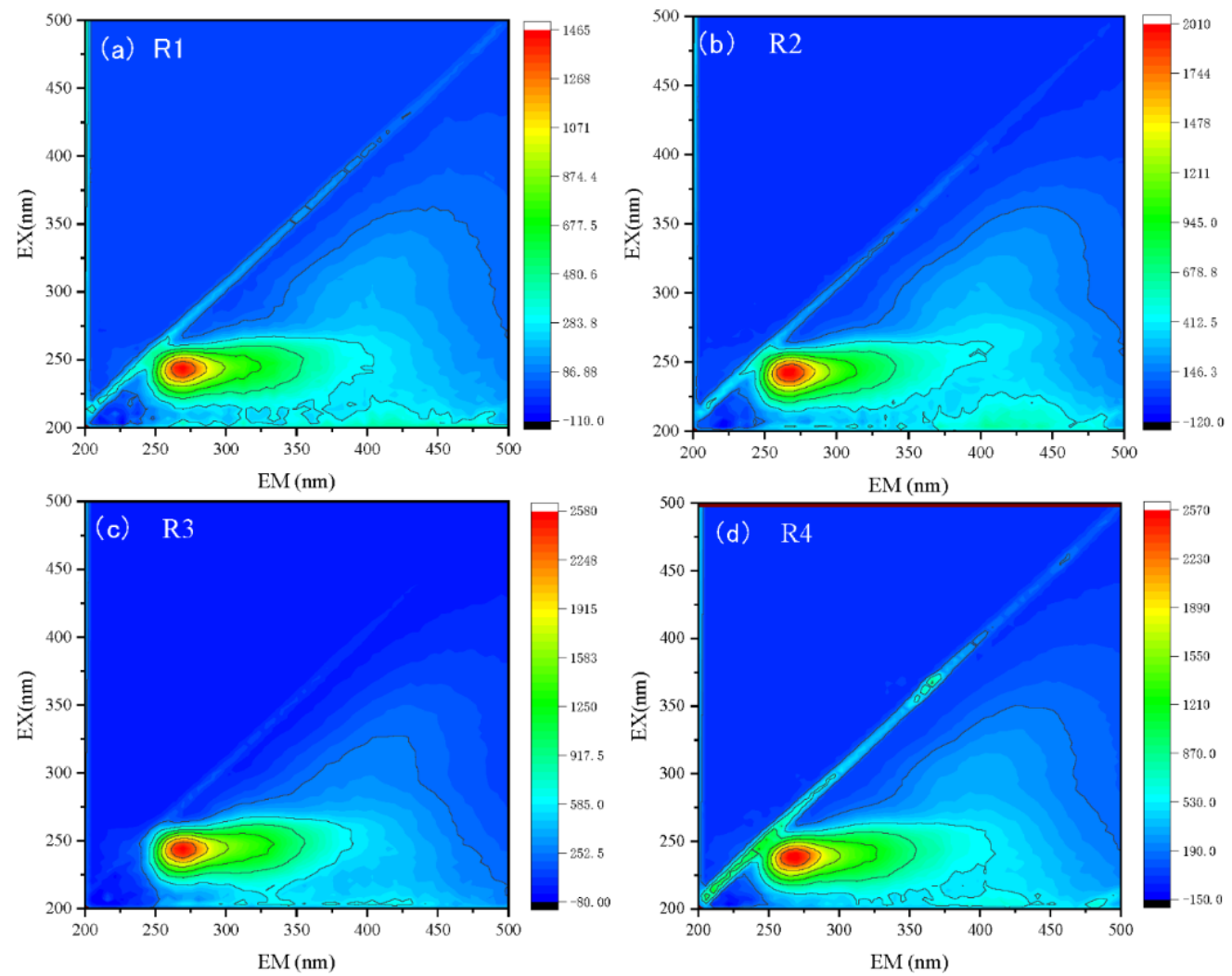

Figure 5. Changes in components (after $3 \mathrm{~h}$ ) in (a) R1 (control test), (b) R2 (with $0.1 \mathrm{mg} / \mathrm{L} \mathrm{OTC),}$ (c) R3 (with $0.5 \mathrm{mg} / \mathrm{L} \mathrm{OTC),} \mathrm{and} \mathrm{(d)} \mathrm{R4} \mathrm{(with} 1 \mathrm{mg} / \mathrm{L} \mathrm{OTC).}$

These results were consistent with previous findings, which may show that the presence of antibiotics can expedite the release of extracellular polymeric substances (EPS), thus promoting cell rupture and increasing the production of dissolved organic matter [25,31]. EPS are high-molecular polymers excreted by microorganisms. As the main components of EPS, proteins provide a binding site for bacteria [33]. Functional groups (such as the carboxyl, amine, and hydroxyl groups) and hydrophobic regions on the proteins can bind to toxic substances (for example OTC), accompanied by the release of large amounts of EPS. As a consequence, the presence of OTC expedited the release of EPS. In addition, EPS can be bound with toxic substances, resulting in lower concentrations of toxic pollutants in the external environment [24,34]. In terms of the degradable substrate producing VFAs, solubilization is generally considered a rate-limiting step of anaerobic digestion. Once solubilization is enhanced, more substrate can be produced to produce VFAs, which is very important and beneficial for subsequent digestion processes. The rupture of these cells is key to the solubilization process and thus affects the production of VFAs $[25,30]$.

Based on these results, the effect of $1.0 \mathrm{mg} / \mathrm{L}$ OTC on the entire process of the anaerobic reaction system may be as follows (Figure 6). First, it promotes the rupture of cells, thereby enhancing the biodegradability of soluble organic matter and increasing the production of soluble organic matter. Second, the formation of more soluble organic matter provides conditions for the formation of VFAs, which in turn promotes acidification. Finally, to a certain extent, the activity of microorganisms is inhibited, the production of methane is inhibited, the lag period of methane is prolonged, and VFAs temporarily accumulate in the system. 


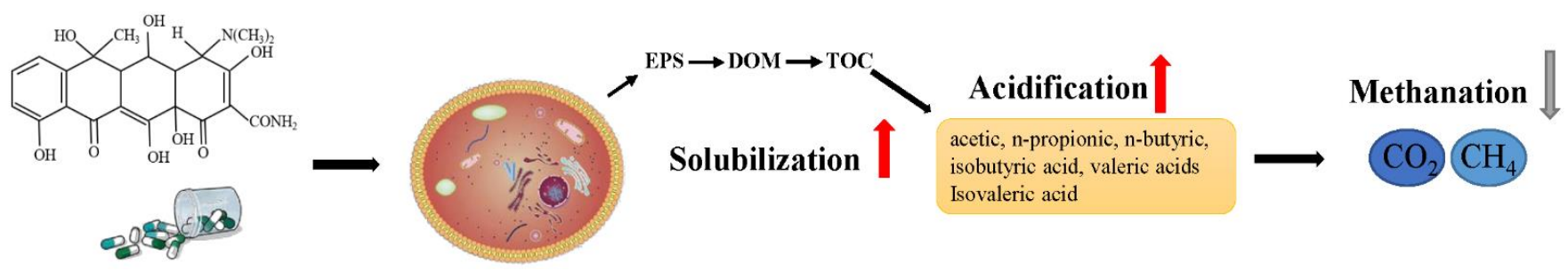

Figure 6. Schematic representation of the effect of OTC on the anaerobic fermentation of swine manure.

\subsection{Degradation of OTC during Anaerobic Digestion}

Figure $4 \mathrm{~b}$ shows the changes in the OTC concentrations in the anaerobic reaction system. At the beginning of the experiment, the OTC concentration dropped rapidly, reaching degradation rates of $73.29 \%, 88.75 \%, 96.93 \%$, and $97.05 \%$ at the end of the experiment for R2, R2, R3, and R4, respectively. A previous study on OTC removal during the anaerobic digestion of swine manure obtained similar values [35]. These results suggest that thermophilic anaerobic digestion has a high degradation ability for OTC, which increases with increasing OTC concentrations within the experimental range.

The degradation of OTC follows the first-order kinetic Equation (3), except in the control group, and higher OTC amounts result in a better curve fit. The estimated parameters are presented in Table 3 . The lowest degradation rate constant was estimated to be 0.6455 at day 1 for R2, whereas the highest degradation rate constant was 1.3698 at day 1 for R4. Our resulting degradation rate was therefore higher than those found in previous studies. For example, the degradation rate of OTC $(10 \mathrm{mg} / \mathrm{L})$ under medium temperature conditions, studied by Alvarez, was 0.052 [2], most likely because high temperatures accelerated the degradation and adsorption of OTC. Similarly, Wu pointed out that the degradation rate of tetracycline in swine manure increased with increasing temperatures, reaching a maximum at $55^{\circ} \mathrm{C}$ [36]. The degradation rate was generally higher in the reactor with a higher OTC concentration, indicating the effect of bioavailability on OTC degradation [2]. In this study, the significant OTC removal may be due to biodegradation and sludge adsorption, which are the main antibiotic removal methods in the biological process [18]. The OTC contains $\mathrm{OH}$ active groups that provide a graft site, making it biodegradable [17]. In addition, OTC can also be degraded during the acidogenic process because the dimethylamine in OTC can isomerize with a reversible reaction under acidic conditions [17].

Table 3. Fitting results of the degradation kinetics of swine manure in the anaerobic process using a simple first-order kinetic model.

\begin{tabular}{|c|c|c|c|c|}
\hline Key Parameters & R1 (0 mg/L) & $\mathrm{R} 2(0.1 \mathrm{mg} / \mathrm{L})$ & R3 (0.5 mg/L) & $\mathrm{R} 4(1.0 \mathrm{mg} / \mathrm{L})$ \\
\hline $\mathrm{k}\left(\mathrm{d}^{-1}\right)$ & / & 0.65 & 0.98 & 1.37 \\
\hline $\mathrm{R}^{2}$ & / & 0.70 & 0.82 & 0.91 \\
\hline Degradation efficiency & 0.73 & 0.89 & 0.97 & 0.97 \\
\hline
\end{tabular}

\section{Conclusions}

Previous studies have found that OTC addition to anaerobic reactor systems $(0.1,0.5$, and $1.0 \mathrm{mg} / \mathrm{L}$ ) can promote cell rupture, thereby increasing the production of dissolved organic matter DOM and TOC. Group R2 ( $0.1 \mathrm{mg} / \mathrm{L}$ OTC) showed no significant effect on methane production and VFA accumulation, whereas R3 $(0.5 \mathrm{mg} / \mathrm{L}$ OTC) and R4 $(1.0 \mathrm{mg} / \mathrm{L}$ OTC) could inhibit methane production and prolong the lag period to a certain extent. The inhibition rate of methane accumulation was divided into $4.03 \%$ and $14.12 \%$. At the same time, the peak value of VFAs increased by $37 \%$ and $65 \%$ with the temporary accumulation of propionic acid. Group R3 ( $0.5 \mathrm{mg} / \mathrm{L}$ OTC) showed no accumulation of VFAs, and R4 $(1.0 \mathrm{mg} / \mathrm{L}$ OTC) had small but insignificant VFA accumulation in the final stage.

The overall effect of $0.1 \mathrm{mg} / \mathrm{L}$ OTC on the anaerobic reaction system may be the promotion of cell rupture, thereby promoting the production of dissolved organic matter. 
Soluble organic matter provides conditions for the formation of VFAs, which in turn promotes acidification. Finally, the methanogen was suppressed to a certain extent by OTC, which reduced methane production and caused the temporary accumulation of VFAs.

The research results of this article can provide a theoretical basis and reference for the high-temperature anaerobic digestion of pig wastewater containing OTC.

Author Contributions: Conceptualization, Z.F. and M.Z.; methodology, Z.F. and X.L.; software, Z.F.; validation, Z.F. and Q.S.; formal analysis, Z.F.; investigation, Z.F. and X.C.; data curation, Z.F. and C.J.; writing—original draft preparation, Z.F.; writing—review and editing, Z.F. and X.L.; visualization, Z.F. and Z.H.; supervision, X.L.; project administration, X.L. All authors have read and agreed to the published version of the manuscript.

Funding: This research was funded by the National Major Science and Technology Program for Water Pollution Control and Treatment (Grant No.2017ZX07602-001).

Institutional Review Board Statement: Not applicable.

Informed Consent Statement: Not applicable.

Data Availability Statement: Not applicable.

Acknowledgments: The authors would like to thank National Major Science and Technology Program for Water Pollution Control and Treatment (Grant No.2017ZX07602-001) and ABA Chemicals for their support and donations.

Conflicts of Interest: The authors declare no conflict of interest.

\section{References}

1. De Liguoro, M.; Cibin, V.; Capolongo, F.; Halling-Sørensen, B.; Montesissa, C. Use of oxytetracycline and tylosin in intensive calf farming: Evaluation of transfer to manure and soil. Chemosphere 2003, 52, 203-212. [CrossRef]

2. Alvarez, J.A.; Otero, L.; Lema, J.M.; Omil, F. The effect and fate of antibiotics during the anaerobic digestion of pig manure. Bioresour. Technol. 2010, 101, 8581-8586. [CrossRef]

3. Zheng, W.; Zhang, Z.; Liu, R.; Lei, Z. Removal of veterinary antibiotics from anaerobically digested swine wastewater using an intermittently aerated sequencing batch reactor. J. Environ. Sci. 2018, 65, 8-17. [CrossRef]

4. Ke, X.; Wang, C.; Li, R.; Zhang, Y. Effects of Oxytetracycline on Methane Production and the Microbial Communities During Anaerobic Digestion of Cow Manure. J. Integr. Agric. 2014, 13, 1373-1381. [CrossRef]

5. Jiang, J.; Sui, J.; Wu, S.; Yang, Y.; Wang, L. Prospects of anaerobic digestion technology in China. Tsinghua Sci. Technol. 2007, 12, 435-440. [CrossRef]

6. Kardos, L.; Juhasz, A.; Palko, G.; Olah, J.; Zaray, G. Comparing of mesophilic and thermophilic anaerobic fermented sewage sludge based on chemical and biochemical tests. Appl. Ecol. Environ. Res. 2011, 9, 293-302. [CrossRef]

7. Watanabe, H.; Kitamura, T.; Ochi, S.; Ozaki, M. Inactivation of pathogenic bacteria under mesophilic and thermophilic conditions. Water Sci. Technol. 1997, 36, 25-32. [CrossRef]

8. Lins, P.; Reitschuler, C.; Illmer, P. Impact of several antibiotics and 2-bromoethanesulfonate on the volatile fatty acid degradation, methanogenesis and community structure during thermophilic anaerobic digestion. Bioresour. Technol. 2015, 190, 148-158. [CrossRef]

9. Beneragama, N.; Lateef, S.A.; Iwasaki, M.; Yamashiro, T.; Umetsu, K. The combined effect of cefazolin and oxytertracycline on biogas production from thermophilic anaerobic digestion of dairy manure. Bioresour. Technol. 2013, 133, 23-30. [CrossRef]

10. Cetecioglu, Z.; Ince, B.; Gros, M.; Rodriguez-Mozaz, S.; Barcelo, D.; Ince, O.; Orhon, D. Biodegradation and reversible inhibitory impact of sulfamethoxazole on the utilization of volatile fatty acids during anaerobic treatment of pharmaceutical industry wastewater. Sci. Total Environ. 2015, 536, 667-674. [CrossRef]

11. Garcia-Sanchez, L.; Garzon-Zuniga, M.A.; Buelna, G.; Estrada-Arriaga, E.B. Tylosin effect on methanogenesis in an anaerobic biomass from swine wastewater treatment. Water Sci. Technol. 2016, 73, 445-452. [CrossRef]

12. Akyol, Ç.; Ince, O.; Cetecioglu, Z.; Alkan, F.U.; Ince, B. The fate of oxytetracycline in two-phase and single-phase anaerobic cattle manure digesters and its effects on microbial communities. J. Chem. Technol. Biotechnol. 2016, 91, 806-814. [CrossRef]

13. Aydin, S.; Cetecioglu, Z.; Arikan, O.; Ince, B.; Ozbayram, E.G.; Ince, O. Inhibitory effects of antibiotic combinations on syntrophic bacteria, homoacetogens and methanogens. Chemosphere 2015, 120, 515-520. [CrossRef]

14. APHA. Standard Methods for the Examination of Water and Wastewater, 20th ed.; American Public Health Association: Washington, DC, USA, 1998.

15. He, C.; Zhao, J.; Wang, S.; Guan, S.; Zhang, Z.; Zhang, Q.; Pan, X.; Jiao, Y. Ammonium bicarbonate pretreatment of corn stalk for improved methane production via anaerobic digestion: Kinetic modeling. Bioresour. Technol. 2019, 292, 122052. [CrossRef] 
16. Dorival-García, N.; Zafra-Gómez, A.; Cantarero, S.; Navalón, A.; Vílchez, J.L. Simultaneous determination of 13 quinolone antibiotic derivatives in wastewater samples using solid-phase extraction and ultra performance liquid chromatography-tandem mass spectrometry. Microchem. J. 2013, 106, 323-333. [CrossRef]

17. Yin, F.; Dong, H.; Ji, C.; Tao, X.; Chen, Y. Effects of anaerobic digestion on chlortetracycline and oxytetracycline degradation efficiency for swine manure. Waste Manag. 2016, 56, 540-546. [CrossRef]

18. Yin, F.; Dong, H.; Zhang, W.; Zhu, Z.; Shang, B. Antibiotic degradation and microbial community structures during acidification and methanogenesis of swine manure containing chlortetracycline or oxytetracycline. Bioresour. Technol. 2018, 250, 247-255. [CrossRef]

19. Arikan, O.A.; Sikora, L.J.; Mulbry, W.; Khan, S.U.; Rice, C.; Foster, G.D. The fate and effect of oxytetracycline during the anaerobic digestion of manure from therapeutically treated calves. Process Biochem. 2006, 41, 1637-1643. [CrossRef]

20. Lay, J.J.; Li, Y.Y.; Noike, T.; Endo, J.; Ishimoto, S. Analysis of environmental factors affecting methane production from high-solids organic waste. Water Sci. Technol. 1997, 36, 493-500. [CrossRef]

21. Chen, Y.; Cheng, J.J.; Creamer, K.S. Inhibition of anaerobic digestion process: A review. Bioresour. Technol. 2008, 99, 4044-4064. [CrossRef]

22. Eryildiz, B.; Taherzadeh, M.J. Effect of $\mathrm{pH}$, substrate loading, oxygen, and methanogens inhibitors on volatile fatty acid (VFA) production from citrus waste by anaerobic digestion. Bioresour. Technol. 2020, 302, 122800. [CrossRef]

23. Cheng, D.L.; Ngo, H.H.; Guo, W.S.; Chang, S.W.; Nguyen, D.D.; Kumar, S.M.; Du, B.; Wei, Q.; Wei, D. Problematic effects of antibiotics on anaerobic treatment of swine wastewater. Bioresour. Technol. 2018, 263, 642-653. [CrossRef] [PubMed]

24. Xu, Q.; Liu, X.; Fu, Y.; Li, Y.; Wang, D.; Wang, Q.; Liu, Y.; An, H.; Zhao, J.; Wu, Y.; et al. Feasibility of enhancing short-chain fatty acids production from waste activated sludge after free ammonia pretreatment: Role and significance of rhamnolipid. Bioresour. Technol. 2018, 267, 141-148. [CrossRef] [PubMed]

25. Chen, H.; Zeng, X.; Zhou, Y.; Yang, X.; Lam, S.S.; Wang, D. Influence of roxithromycin as antibiotic residue on volatile fatty acids recovery in anaerobic fermentation of waste activated sludge. J. Hazard. Mater. 2020, 394, 122570. [CrossRef] [PubMed]

26. Xie, J.; Duan, X.; Feng, L.; Yan, Y.; Wang, F.; Dong, H.; Jia, R.; Zhou, Q. Influence of sulfadiazine on anaerobic fermentation of waste activated sludge for volatile fatty acids production: Focusing on microbial responses. Chemosphere 2019, 219, 305-312. [CrossRef]

27. Khan, M.A.; Ngo, H.H.; Guo, W.S.; Liu, Y.; Nghiem, L.D.; Hai, F.I.; Deng, L.J.; Wang, J.; Wu, Y. Optimization of process parameters for production of volatile fatty acid, biohydrogen and methane from anaerobic digestion. Bioresour. Technol. 2016, 219, 738-748. [CrossRef]

28. Kong, X.; Yu, S.; Xu, S.; Fang, W.; Liu, J.; Li, H. Effect of Fe(0) addition on volatile fatty acids evolution on anaerobic digestion at high organic loading rates. Waste Manag. 2018, 71, 719-727. [CrossRef]

29. Han, Y.; Green, H.; Tao, W. Reversibility of propionic acid inhibition to anaerobic digestion: Inhibition kinetics and microbial mechanism. Chemosphere 2020, 255, 126840. [CrossRef]

30. Luo, J.; Zhang, Q.; Zhao, J.; Wu, Y.; Wu, L.; Li, H.; Tang, M.; Sun, Y.; Guo, W.; Feng, Q.; et al. Potential influences of exogenous pollutants occurred in waste activated sludge on anaerobic digestion: A review. J. Hazard. Mater. 2020, 383, 121176. [CrossRef]

31. Huang, X.; Xu, Q.; Wu, Y.; Wang, D.; Zhong, Q. Effect of clarithromycin on the production of volatile fatty acids from waste activated sludge anaerobic fermentation. Bioresour. Technol. 2019, 288, 121598. [CrossRef]

32. Wang, D.; Wang, Y.; Liu, X.; Xu, Q.; Yang, Q.; Li, X.; Zhang, Y.; Liu, Y.; Wang, Q.; Ni, B.J.; et al. Heat pretreatment assists free ammonia to enhance hydrogen production from waste activated sludge. Bioresour. Technol. 2019, 283, 316-325. [CrossRef]

33. Sheng, G.P.; Yu, H.Q.; Li, X.Y. Extracellular polymeric substances (EPS) of microbial aggregates in biological wastewater treatment systems: A review. Biotechnol. Adv. 2010, 28, 882-894. [CrossRef] [PubMed]

34. Zhang, H.; Jia, Y.; Khanal, S.K.; Lu, H.; Fang, H.; Zhao, Q. Understanding the Role of Extracellular Polymeric Substances on Ciprofloxacin Adsorption in Aerobic Sludge, Anaerobic Sludge, and Sulfate-Reducing Bacteria Sludge Systems. Environ. Sci. Technol. 2018, 52, 6476-6486. [CrossRef] [PubMed]

35. Coban, H.; Ertekin, E.; Ince, O.; Turker, G.; Akyol, C.; Ince, B. Degradation of oxytetracycline and its impacts on biogas-producing microbial community structure. Bioprocess Biosyst. Eng. 2016, 39, 1051-1060. [CrossRef] [PubMed]

36. Wu, X.; Wei, Y.; Zheng, J.; Zhao, X.; Zhong, W. The behavior of tetracyclines and their degradation products during swine manure composting. Bioresour. Technol. 2011, 102, 5924-5931. [CrossRef] [PubMed] 